\title{
CORRECTION
}

View Article Online

View Journal I View Issue

D) Check for updates

Cite this: J. Mater. Chem. C, 2019,

7, 3696

DOI: $10.1039 /$ c9tc90045d

rsc.li/materials-c

\section{Correction: Recent developments in photonic, plasmonic and hybrid nanowire waveguides}

\author{
Sanggon $\mathrm{Kim}^{\mathrm{a}}$ and Ruoxue Yan*ab \\ Correction for 'Recent developments in photonic, plasmonic and hybrid nanowire waveguides' by \\ Sanggon Kim et al., J. Mater. Chem. C, 2018, 6, 11795-11816.
}

The authors regret the omission of an Acknowledgements section from the original article. The correct acknowledgements are as below.

\section{Acknowledgements}

This work was supported by the National Science Foundation under Grant CHE-1654794.

The Royal Society of Chemistry apologises for these errors and any consequent inconvenience to authors and readers.

\footnotetext{
${ }^{a}$ Department of Chemical and Environmental Engineering, University of California, Riverside, USA. E-mail: rxyan@engr.ucr.edu

${ }^{b}$ Materials Science and Engineering Program, University of California, Riverside, USA
} 